\title{
A diplomacia do yuan': breves comentários sobre a internacionalização financeira da China (parte II - evidências e conclusões)
}

\author{
Luíza Cardoso de Andrade* \\ André Moreira Cunha*
}

RESUMO - O presente artigo avalia o processo recente de internacionalização da China, enfatizando sua dimensão monetária. Avalia-se a hipótese do iuane renmimbi se tornar uma moeda internacional como decorrência da ascensão chinesa à condição de potência global.

Palavras-chave: China. Internacionalização monetária e financeira. Iuane renmimbi.

\section{INTRODUÇÃO DA SEGUNDA PARTE}

Esta é parte final do trabalho que analisa os movimentos mais recentes da estratégia de internacionalização da China. No número anterior deste Boletim foram apresentados os aspectos teóricos que condicionam a internacionalização de uma moeda. Evidências preliminares para o caso chinês foram introduzidas para que, aqui, fosse possível complementar a análise. Partiu-se da hipótese de que a China entrou em uma nova etapa de seu processo de internacionalização onde a extroversão financeira está ganhando maior proeminência. Todavia, segue sendo prematuro vislumbrar o yuan renmimbi como uma moeda plenamente conversível e internacional.

\section{CONVERSIBILIDADE E CONTROLE DE CAPITAIS NA CHINA}

Embora seja possível para residentes da China usar o iuane para comprar moedas estrangeiras para pagar importações ou cumprir com obrigações no exterior, há várias restrições à conversão de títulos em iuane em outras moedas, e não é fácil para não residentes comprar títulos denominados em iuane em troca de suas moedas nacionais. Em outras palavras, o iuane é conversível para a maioria das transações em conta corrente, mas para transações de conta capital, sua conversibilidade é muito mais restrita.

\footnotetext{
†A moeda chinesa é denominada Renminbi (RMB ou CNY), termo que significa "a moeda do povo". Iuane é sua unidade de medida.

* Bolsista PIBIC-CNPq na Universidade Federal do Rio Grande do Sul. Endereço eletrônico: luiza.c.andrade@ gmail.com.

** Doutor em economia pela Universidade Estadual de Campinas. É professor do Departamento de Ciências Econômicas da Universidade Federal do Rio Grande do Sul e pesquisador do CNPq. Endereço eletrônico: andre. cunha@ufrgs.br.
} 
A conversibilidade da conta capital é importante porque os agentes, sejam indivíduos ou companhias, buscarão manter em seu poder moedas que possam ser investidas. Caso não tenham opções de aplicações rentáveis para uma moeda, os agentes ficarão apreensivos em aceitá-la como pagamento, a menos que esperem poder passá-la adiante muito rapidamente. De fato, as barreiras à conversibilidade constituem um dos principais empecilhos a um uso internacional mais amplo do iuane.

Se é verdadeiro que ainda há muitas barreiras à conversibilidade do iuane, também é fato que há um movimento - ainda que bastante lento - em direção à liberalização dessas restrições, principalmente daquelas impostas a bancos e outras companhias não financeiras. Ao analisar as mudanças ocorridas nesse sentido e as formas de investimento existentes atualmente, essa abertura foi acompanhada de significativo aumento no fluxo - tanto de entrada quanto de saída - de investimento direto estrangeiro (IDE, daqui para frente).

As reformas que deram início à liberalização dos fluxos de capital e investimento na China começaram em 1979, quando foi permitido que empresas estrangeiras atuassem no país, dentro de regras pré-determinadas. No mesmo ano, foram criadas as Zonas Administrativas Especiais. As facilidades de investimento e atuação nessas quatro regiões foram, em 1984, estendidas a outras 14 unidades administrativas, principalmente na costa chinesa. Em 1986, as reduções de impostos que já eram concedidas nessas áreas se tornaram possíveis para empresas de investimento estrangeiro em todo o país, com atenção especial àquelas voltadas à exportação e aos projetos que se utilizassem de tecnologias mais avançadas para aumentar a capacidade de produção interna.

O governo chinês declarou, em 1999, que pretendia implementar a conversibilidade da conta capital até 2000 . No entanto, com a crise asiática e a importância dos fluxos de capitais (não IDE) nesse processo, a ideia foi abandonada, e o país começou a acumular reservas internacionais ${ }^{1}$. Pode-se perceber, nas iniciativas de liberalização tomadas desde então, que a principal preocupação dos policymakers chineses é com a estabilidade. Nesse sentido, eles buscam restringir a entrada de capitais de curto prazo, tais como investimento em portfólio, e incentivar os fluxos de investimento estrangeiro direto.

Essa política tinha força especial no início do processo de abertura, quando havia uma preocupação maior em estimular a entrada de capitais que pudessem ajudar o país a aumentar seu domínio de tecnologia e a se adaptar melhor ao sistema de mercado, o que também privilegiava os fluxos de IDE, em detrimento do financiamento via dívida externa. Assim, inicialmente os produtores tinham de entrar no país fazendo parcerias com empresas chinesas,

1 Prasad e Wei (2005). 
permitindo que os residentes aprendessem com os eles. Atualmente, já tendo as companhias chinesas adquirido know-how tecnológico e de mercado, empresas totalmente estrangeiras são permitidas (CUNHA; ACIOLY, 2009).

A entrada da China na Organização Mundial do Comércio, em 2001, representou a aceleração do processo de internacionalização financeira. Passou-se a estimular o investimento em outros países por parte de companhias chinesas². No entanto, até 2003 investidores estrangeiros praticamente não tinham acesso a títulos e ações da China continental e apenas os bancos chineses eram autorizados a investir diretamente no exterior - e somente na forma de instrumentos de renda fixa.

Em 2003, foi criado o esquema de Qualified Foreign Institutional Investor (QFII, de agora em diante), que permite que empresas estrangeiras que satisfizerem determinadas condições comprem títulos chineses, visando a impulsionar o mercado doméstico de ações. Como veremos a seguir, o QFII continua vigente ainda hoje com algumas alterações, porém os investimentos feitos através dele ainda são bastante limitados no volume permitido e nas possibilidades de repatriamento, além de terem de ser aprovados pelo governo.

Em abril de 2006, foi criado o Qualified Domestic Institutional Investor (QDII), que permite que indivíduos e companhias chinesas realizem investimentos em portfólio fora do país através de intermediários autorizados, e que as seguradoras domésticas convertam yuan em dólar para investir em títulos estrangeiros. Os investidores e intermediários têm de satisfazer determinadas condições e há quotas limitando os investimentos em ambos os casos.

Em junho do mesmo ano, novas medidas foram tomadas para estimular a saída de capitais domésticos do país, buscando diminuir o superávit externo. Tais medidas - que também estabeleciam quotas para a saída de investimentos, porém simplificando os processos de aprovação, além de permitir que os lucros sejam reinvestidos no exterior - visam a garantir o acesso a recursos naturais, principalmente na África, e a encorajar o crescimento das grandes companhias chinesas.

Dessa forma, como chamam à atenção Ma e McCauley (2007), os esquemas de QFII e QDII buscam institucionalizar a administração dos fluxos em portfólio que entram e saem da China, possibilitando um maior controle sobre eles, numa tentativa de diminuir os riscos de instabilidade por eles representados. Assim, ambos envolvem procedimentos de pré-aprovação, gerenciamento de quotas, regras para conversão em moedas estrangeiras, restrição de instrumentos e entrega regular de relatórios.

Em janeiro de 2007, o banco central chinês anunciou um teto de US\$50.000 por pes-

2 Ma e McCauley (2007). 
soa por ano para livre conversão entre o iuane e moedas estrangeiras por residentes chineses. Dentro desse limite, os residentes chineses podem transferir seus fundos para além das fronteiras livremente ${ }^{3}$. Em agosto desse mesmo ano, a State Administration for Foreign Exchange anunciou que investidores chineses poderiam abrir contas na subsidiária do Banco da China em Tianjin para comercializar ações listadas no mercado de Hong Kong. No entanto, essa medida foi revertida em novembro.

Em julho de 2010, uma nova medida foi anunciada, o chamado mini-QFII, que permitirá que, de Hong Kong, depósitos em iuane no exterior sejam canalizados para os mercados financeiros chineses. O programa, que teria início ainda nesse ano, tem tamanho inicial esperado de US $\$ 1,5$ bilhão, podendo chegar a US $\$ 15$ bilhões, e complementa o QFII, que atualmente permite que investidores estrangeiros negociem as chamadas " $A$ shares" " e tem teto de US $\$ 30$ bilhões.

GRÁFICO 1 - ENTRADA DE IDE DE ECONOMIAS SELECIONADAS, 1983-2007 (ESTOQUE, \% TOTAL MUNDIAL)

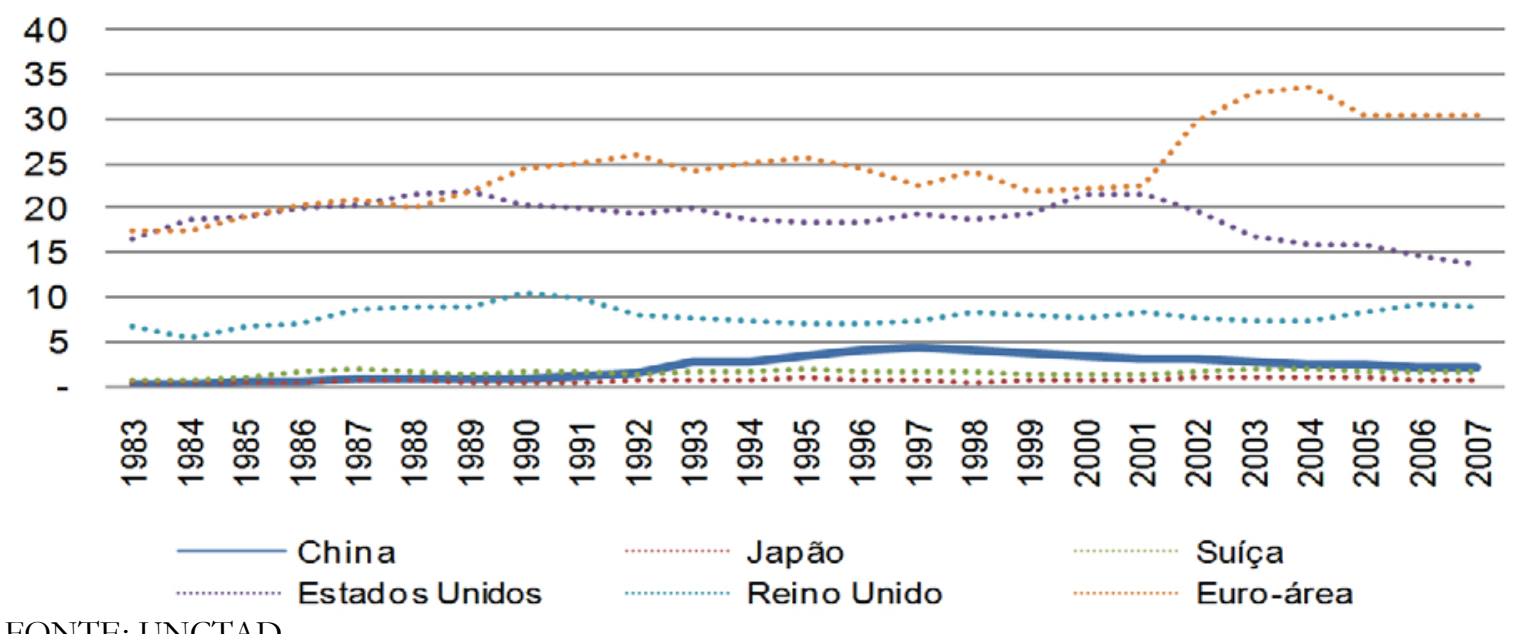

FONTE: UNCTAD.

Alguns autores têm dúvidas quanto à efetividade dos controles de capitais na China. Ma e McCauley (2007), por exemplo, observam que as reações dos fluxos de conta capital, assim como os de conta corrente, às condições de mercado, segundo eles, poderia sugerir que os controles não funcionam como deveriam. Efetivas ou não, em 2000 um estudo da Pricewaterhouse Coopers indicou que, dos países analisados, a China estava entre os únicos cinco que ofereciam restrições ao IDE em todas as categorias analisadas 5 . Já em 2005, Prasad e Wei estimaram que os controles de capitais ainda eram aplicados a cerca de 25\% das categorias do FMI. Pode-se

3 Ma e McCauley (2007).

4 "A shares" são ações de companhias da China continental negociadas em yuan nos mercados de Shanghai e Shenzhen.

5 Prasad e Wei (2005). 
notar que há avanços em direção à liberalização, mas que o caminho a percorrer ainda é longo.

Como se pode ver nos Gráficos 1 e 2, essas políticas de incentivo à entrada de IDE tiveram êxito, e desde a década de 1980 a China está entre os principais destinos de investimento no mundo.

GRÁFICO 2 - ENTRADA DE IDE NA CHINA, 1979-2009 (FLUXO, US\$ BILHÕES)

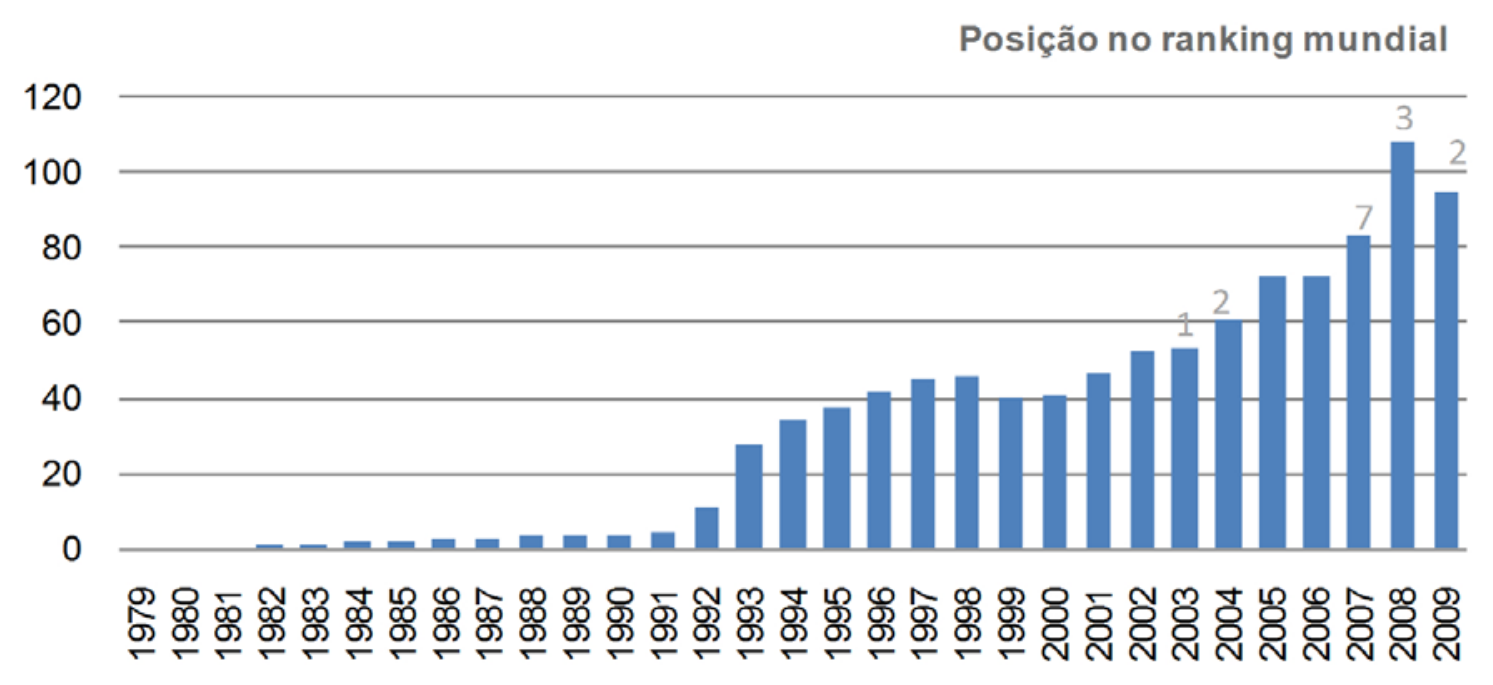

FONTE: UNCTAD.

No que diz respeito à saída de IDE do país, os Gráficos 3 e 4 mostram que os fluxos aumentaram bastante a partir da década de 1990, porém ainda eram pouco volumosos até 2007. Em junho desse ano, o país anunciou a criação da China Investment Corporation (CIC), através da qual vem diversificando aplicações de suas reservas. Inicialmente este fundo soberano tinha um capital de US $\$ 200$ bilhões. Ademais, empresas estatais e grandes conglomerados privados vêm ampliando a aquisição de ativos no exterior, como parte da política governamental de “Going Global'. A busca de acesso a recursos naturais estratégicos, mercados e tecnologias de fronteira estão no centro deste movimento, que parece ter ganhado força após a crise financeira global (MILLER, 2010). Note-se que, em 2009, o país já era o $16^{\circ}$ maior investidor em termos de estoque e o $6^{\circ}$ no fluxo anual.

Ma e Haiwen (2009) estimavam que, em 2007, a China já possuía a segunda maior posição credora líquida do mundo. A diferença entre seus ativos e passivos internacionais equivalia a 30\% do PIB. Desde então suas reservas internacionais, o principal componente dos ativos, não pararam de crescer, atingindo o montante de US\$2,6 trilhões ao final de 2010, ou, 46\% do $\mathrm{PIB}^{6}$.

6 Ver: http://www.dbresearch.com; http://www.hangseng.com/ermt/eng/fxmv/pdf/chem_e.pdf (China Economic Monitor, December, 2010). 
GRÁFICO 3 - SAÍDA DE IDE EM ECONOMIAS SELECIONADAS , 1983-2009(ESTOQUE, \% DO TOTAL MUNDIAL)

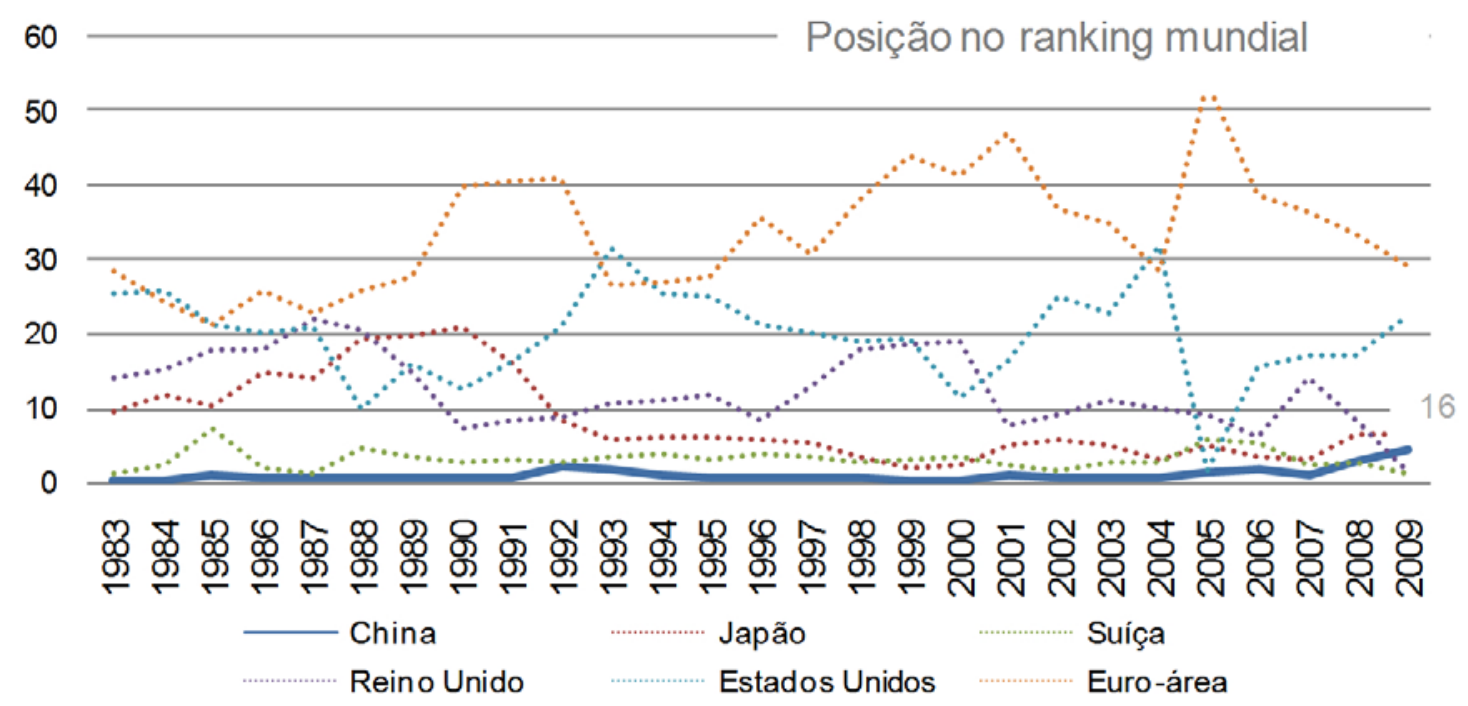

FONTE: UNCTAD.

GRÁFICO 4 - SAÍDA DE IDE DA CHINA, 1982-2009 (FLUXO, US\$ BILHÕES)

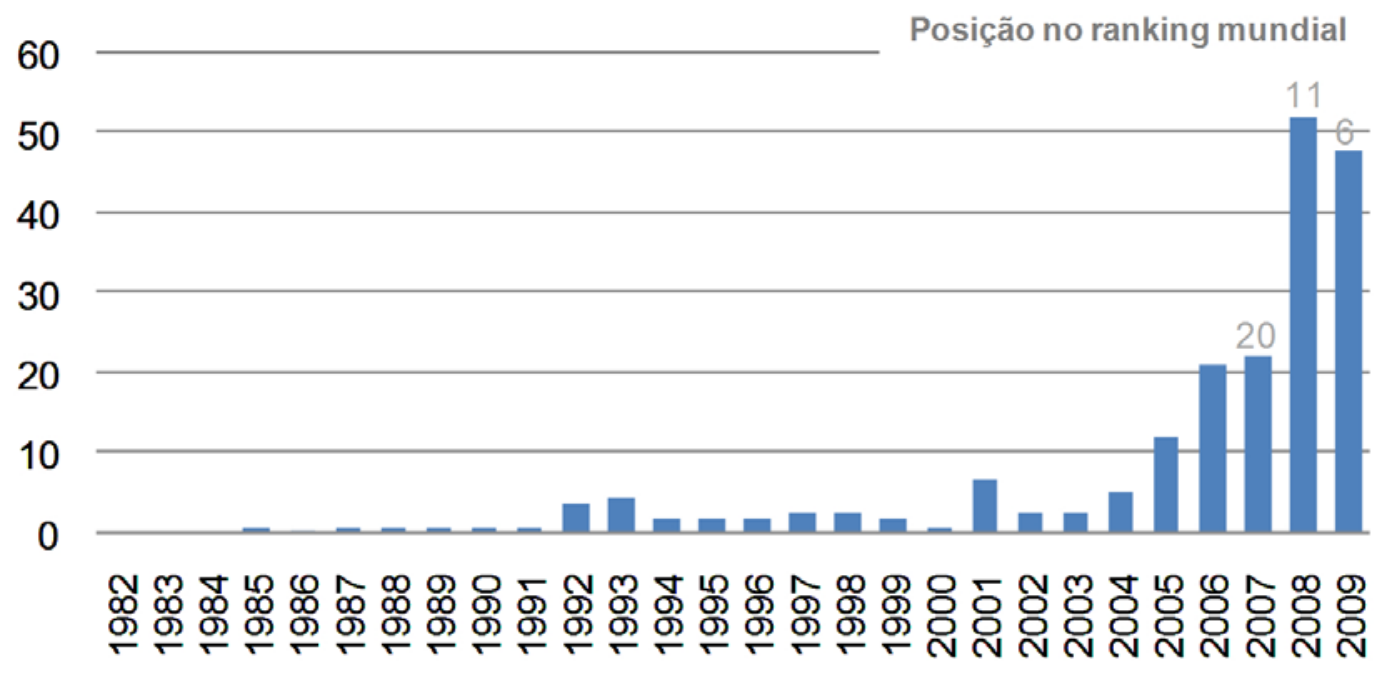

FONTE: UNCTAD.

Ma e Haiwen (2009) estimavam que, em 2007, a China já possuía a segunda maior posição credora líquida do mundo. A diferença entre seus ativos e passivos internacionais equivalia a 30\% do PIB. Desde então suas reservas internacionais, o principal componente dos ativos, não pararam de crescer, atingindo o montante de US\$2,6 trilhões ao final de 2010, ou, 46\% do $\mathrm{PIB}^{7}$.

7 Ver: http://www.dbresearch.com; http://www.hangseng.com/ermt/eng/fxmv/pdf/chem_e.pdf (China Economic Monitor, December, 2010). 


\section{SISTEMA BANCÁRIO E FINANCEIRO NA CHINA}

Até 1979, apenas o Banco do Povo da China (BPC), cujas funções hoje se restringem às de um Banco Central, era a única instituição bancária existente no país. Tampouco existiam mercados financeiros, de forma que o próprio BPC era responsável pela canalização dos recursos para investimento. Assim, ele alocava os fundos entre empresas estatais e instâncias de governo de acordo com um planejamento previamente estabelecido. Desde então, foram criados mais quatro grandes bancos nacionais, o Banco da Agricultura da China, o Banco da China, o Banco da Construção da China e o Banco Industrial e Comercial da China, todos estando principalmente voltados para o financiamento de empresas estatais ${ }^{8}$.

A partir de 1995, o governo chinês realizou reformas para transformar os Quatro Grandes em bancos comerciais. Foram criados novos bancos para realizar os policy lendings e tem sido feito um esforço para retirar os non-performing loans dos balanços. Além disso, o BPC reformou os padrões regulatórios e as normas para a realização de empréstimos. Em 2003 teve início um novo processo de reformas nos bancos comerciais para aumentar sua competitividade antes de abrir o setor bancário à concorrência externa, o que deveria acontecer em 2006 como parte do acordo para a entrada da China na OMC - até então, a participação máxima de investidores estrangeiros na propriedade dos bancos permitida era de $25 \%$. Os dois bancos que serviram de piloto para a reforma foram recapitalizados, tiveram sua governança corporativa e seu gerenciamento de risco reestruturados, sua transparência aumentada e seus non-performing loans solucionados.

Além de tornar os bancos chineses mais competitivos, essas reformas deveriam atrair investidores estratégicos para o setor e prepará-los para que possam ser listados em bolsas estrangeiras. Os investidores estrangeiros contribuiriam não apenas com capital, mas também com a experiência adquirida em gerenciamento e governança corporativa, além de trazer novos produtos, aumentando a eficiência e o potencial de retorno dos bancos chineses. Com os bancos listados em bolsas de valores estrangeiras, haveria pressão do mercado para que se adotassem os padrões internacionais de precisão e transparência, e a performance dos bancos passaria a ser avaliada em termos de eficiência e lucratividade.

Em 2005 os bancos já estavam próximos de alcançar seus objetivos quantitativos. Apesar do sucesso da reforma nos bancos-piloto, ainda há forte influência do partido nos bancos; mesmo quando não estão nominalmente presentes nos conselhos, decisões de grande importância ainda são tomadas por eles extra-oficialmente. Além disso, embora a qualidade dos empréstimos tenha melhorado consideravelmente desde 2000, os antigos non-performing loans

8 Cunha e Acioly (2009). 
ainda pesam sobre os balanços dos Quatro Grandes, a despeito dos esforços para liquidá-los.

Vem sendo feito um esforço de melhoramento da supervisão bancária, sobretudo a partir de 2004, através da China Banking Regulatory Comission, principalmente no que diz respeito à classificação de ativos e à adequação de capital - mais uma vez tentando solucionar o problema dos non-performing loans. No entanto, o sistema regulatório ainda não está bem desenvolvido. O banco central (BPC), por exemplo, controla a oferta monetária e regula o crédito através de controle direto sobre as taxas de empréstimos e depósitos dos bancos ${ }^{9}$. A regulação dos bancos e dos mercados financeiros não é transparente, e as diferentes agências reguladoras às vezes tem funções sobrepostas ${ }^{10}$. Além disso, dado que a maioria dos players são controlados pelo governo e a falta de competição inibe a inovação no mercado, o sistema regulatório ainda não foi testado como seria em um mercado mais aberto, podendo se mostrar inadequado conforme as restrições foram sendo liberalizadas.

Historicamente, os bancos estatais têm privilegiado como critério para escolha de seus financiamentos a manutenção do emprego e da estabilidade social. A principal desconfiança internacional com relação ao sistema bancário chinês é justamente sua hesitação em adotar critérios como risco e rentabilidade ao efetuar empréstimos.

Segundo Dobson e Kashyap (2006), o governo insiste em manter o controle acionário nos bancos justamente para preservar o poder de canalizar diretamente o crédito. Dado que as maiores e mais lucrativas empresas estatais costumam se financiar através de fundos retidos e que o mercado de títulos ainda é muito pouco desenvolvido, a maior parte do financiamento na China é feita através dos bancos. Assim, resta a eles financiar as empresas que oferecem maior risco.

A forte presença estatal no sistema bancário e a interferência administrativa do banco central distorcem as decisões de crédito ao enfatizar restrições setoriais sobre decisões baseadas no risco e na produtividade de tomadores de empréstimos e projetos. Os maiores bancos chineses ainda dão mostras de que priorizam critérios políticos em suas decisões de crédito.

Embora esse seja apontado como o principal problema do sistema bancário chinês, outros autores ressaltam ainda problemas de segmentação dos mercados, dificuldades de precificação pela ausência de taxas de benchmark, baixa liquidez, falta de modelos contábeis modernos e de transparência por parte das empresas que lançam títulos, falta de disciplina de mercado e de educação dos investidores e subdesenvolvimento do mercado de crédito devido à recente aprovação das leis de falência, com as quais ainda há pouca familiaridade (UBS, 2006; ZHOU,

9 Naughton (2007). 10 UBS (2006). 
2005).

Como enfatizado anteriormente, os bancos enfrentam pouca concorrência de mercados de dívidas, já que mercados de dívidas corporativas, na forma de commercial papers e asset backed securities estão apenas começando a ser estabelecidos. As grandes empresas estatais têm acesso privilegiado aos bancos e utilizam largamente os lucros retidos como fonte de financiamento. Comparados aos mercados de países vizinhos como Coreia, Malásia e Tailândia, os mercados chineses ainda estão muito pouco desenvolvidos.

O lançamento de títulos corporativos é bastante restrito, sendo supervisionado pelo banco central e agências reguladoras. Recentemente, com a eliminação da obrigatoriedade de aprovação dos títulos lançados por comissões de planejamento, o número de títulos lançados começou a acelerar.

Assim, como se pode observar, no que diz respeito às reformas nos sistemas bancário e financeiro, a China se vê dividida entre as pressões internacionais para a abertura dos mercados e adoção de padrões de eficiência e a preocupação do governo em manter o emprego e a estabilidade. Apesar dos avanços que já foram feitos em direção a um setor bancário mais transparente, com adoção de critérios de mercado, ainda há distorções e novas reformas serão necessárias. Essas reformas permitirão uma alocação mais eficiente da elevada poupança privada do país e facilitarão a transmissão da política monetária. Elas também serão decisivas para que os mercados financeiros chineses venham a se desenvolver. Para que o remninbi se torne atrativo internacionalmente, a China terá de desenvolver mercados financeiros líquidos e profundos. Como ressalta Eichengreen (2009a, 2009b), isso significa que o país terá de desenvolver sistema de liquidação e compensação mais confiáveis e transparentes, ativos de benchmark, curva de rendimento bem definida e massa crítica de participantes do mercado.

Portanto, o desenvolvimento dos mercados financeiros, a continuação das reformas no sistema bancário e a conversibilidade da conta capital são objetivos econômicos interligados e que devem ser trabalhados conjuntamente. Embora eles venham sendo abordados, demonstrando certo interesse do governo chinês na realização dessas mudanças, nota-se também que ele não está disposto a abrir mão de suas políticas de manutenção do emprego e de proteção do país contra a instabilidade financeira. Isso determina o gradualismo das reformas no país. Considerando que uma vez que elas tenham sido realizadas ainda será necessário um período de adaptação e de consolidação das mudanças até que os detentores de riqueza criem confiança nos ativos emitidos e liquidados na moeda chinesa, ainda há um longo caminho a ser percorrido até que o iuane seja amplamente utilizado internacionalmente. 


\section{CONSIDERAÇÕES FINAIS}

Este artigo procurou avaliar algumas evidências dos movimentos mais recentes da estratégia de internacionalização da China. Enfatizou-se a questão da possibilidade do iuane renmimbi se tornar uma moeda internacional capaz de rivalizar o dólar e outras moedas de reserva. Após uma breve revisão da literatura sobre as precondições para a internacionalização de uma moeda, constatou-se que, a despeito de seu peso crescente na economia mundial, especialmente na renda e fluxos de comércio e investimento direto, a China não preenche todas as condições previamente levantadas, particularmente no que se refere ao grau de conversibilidade do iuane renmimbi, desenvolvimento de suas instituições monetárias e financeiras, bem como de restrições à livre mobilidade de capitais. Ainda assim, constatou-se que a economia chinesa entrou em uma nova etapa de seu processo de internacionalização onde a extroversão financeira passou a ter maior proeminência.

É razoável supor que o papel de destaque a que a China foi alçada na economia mundial deve ser reforçado nos próximos anos. A nova postura que o governo chinês vem apresentando desde a crise de 2008 com relação ao uso internacional de sua moeda, como fica claro por sua promoção de acordos de swap com diversos países, representa mais um passo no processo de internacionalização da economia chinesa. O fato de que o governo agora adota uma postura favorável à internacionalização do iuane renmimbi e vem, portanto, promovendo políticas para reforçar sua influência global naturalmente facilitará esse processo.

No entanto, o ritmo das reformas nos mercados financeiros, no sistema bancário e no regime de conversibilidade mostram que tal processo se dará gradualmente e que a principal preocupação chinesa é com manutenção do elevado crescimento com estabilidade macroeconômica e política. As recorrentes crises financeiras dos últimos quinze anos parecem ter reforçado a estratégia gradualista. Se levarmos em conta o longo caminho que ainda deve ser percorrido, isso significa que o yuan renmimbi não representará, em um horizonte próximo, uma ameaça à hegemonia do dólar ou do euro, principalmente no que diz respeito aos seus usos como constituintes de reservas estrangeiras.

Até alcançar de fato o status de moeda internacional, no entanto, é provável que a moeda chinesa passe a ser mais amplamente utilizada, num primeiro momento, na região em que a influência econômica do país é mais forte, ou seja, entre os países do Leste Asiático. Atualmente, já é possível observar o uso do yuan nesses países, principalmente em áreas turísticas. Nos próximos anos esse uso deve ser ampliado, num primeiro momento para a realização de transações comerciais com a China. O processo de integração regional tem sido, cada vez mais, sino-cêntrico, tendência que deve se reforçar neste período pós-crise financeira global 
(CUNHA, 2010).

\section{REFERÊNCIAS}

BOTTELIER, P. International monetary reform and the future of the remninbi. China Brief. Volume IX, Issue 11, 2009. Disponível em: <http://www.jamestown.org/single/?no_ cache $=1 \&$ tx_ttnews[tt_news] $=35039>$. Acesso em 11/2010.

CHEN, H., PENG, W. The potential of the renminbi as an international currency. China Economic Issues, November, 2007. Disponível em: <http://www.info.gov.hk/hkma/eng/research/cei/cei_f.htm>. Acesso em 07/2010.

CHINN, M., FRANKEL, J. Will the euro eventually surpass the dollar as leading international reserve currency? NBER Working Paper 11510, 2005.

COHEN, BENJAMIN J. The future of sterling as an international currency, London: Macmillan, 1971.

CUNHA, A. M. Integração monetária e financeira na Ásia-Pacífico: o que podemos esperar depois da crise. In: XV Encontro Nacional de Economia Política, 2010, São Luis. CD-Room (Anais do XV Encontro Nacional de Economia Política). São Paulo: Sociedade de Economia Política, 2010.

CUNHA, A. M., BIANCARELLI, A. M., PRATES, D. M. A diplomacia do yuan fraco. Revista de Economia Contemporânea, v. 11, p. 525-562, 2007.

CUNHA, A. M., SILVA, L. A. China: ascensão à condição de potência global, características e implicações. In: José Celso Cardoso Jr.; Luciana Acioly; Milko Matijascic. (Org.). Trajetórias recentes de desenvolvimento: estudos de experiências internacionais selecionadas. Brasília, 2009, v. 2, p. 343-396.

DOBSON, W., KASHYAP, A. The contradictions in China's gradualist banking reforms. Brookings Papers on Economic Activity., V. 2. September, 2006.

DOBSON, W., MASSON, P., Will the renminbi become a world currency? China Economic Review, 20, 124-135, 2009.

EICHENGREEN, B. A globalização do capital. São Paulo: Editora 34, 2003.

EICHENGREEN, B. Sterling's past, dollar's future: historical perspectives on reserve currency competition. NBER Working Paper No. 11336, Cambridge, MA, May, 2005.

EICHENGREEN, B. The dollar dilemma. Foreign Affairs, September/October, 2009a.

EICHENGREEN, B. The irresistible rise of the renminbi. Disponível em: < http://www.project-syndicate.org >. Em 23 de novembro de 2009b.

HELLEINER, E. Political determinants of international currencies: What future for the US dollar? Review of International Political Economy, 15:3 August, 354-378, 2008.

KANG, D. C. China rising: peace, power and order in East Asia. Columbia University Press, 2007.

KENEN, P. The Role of the Dollar as an International Reserve Currency, Occasional Papers no. 13, Group of Thirty, 1983.

KRUGMAN, P. The international role of the dollar: theory and prospect. In: Bilson, J. F. O., R. Marston, R. (eds) Exchange rate theory and practice, Chicago: University of Chicago, 
1984.

MA, G., HAIWEN, Z. China's evolving external wealth and rising creditor position. BIS Working Papers, No 286, 2009.

MA, G., MCCAULEY, R. N. Do China's capital controls still bind? Implications for monetary autonomy and capital liberalization. BIS Working Papers No. 233, 2007.

MILLER, K. Coping with China's financial power. Foreign Affairs, July/August, 2010.

NAUGHTON, B. The chinese economy: transitions and growth. Cambridge, MA: MIT Press, 2007.

PODPIERA, R. Progress in China's banking sector reform: has bank behavior changed? IMF Working Paper WP06/71, Washington, DC: IMF, 2006.

PRASAD, E., SHANG-JIN WEI. The chinese approach to capital inflows: patterns and possible explanations, NBER Working Paper 11306, May, 2005.

ROUBINI, N. The almighty renminbi? The New York Times, May 13th, 2009. Disponível em:< http://www.nytimes.com/2009/05/14/opinion/14Roubini.html>.

SHIRK, S. L. China: fragile superpower. Oxford University Press, 2007.

TAVLAS, G.S. On the international use of currencies: the case of the deutsche mark. Princeton essays in international finance, No. 181, March, 1991.

THIMANN, C. Global role of currencies. ECB Working Papers, n. 1031, March, 2009. Disponível em: <http://www.ecb.europa.eu/pub/pdf/scpwps/ecbwp1031.pdf>. Acesso em 07/ 2010.

UBS. China bond market research. Londres, 4 de dezembro de 2006.

ZHOU, X. China's corporate bond market development: lessons learned. BIS Papers No. 26. Basle: Bank for International Settlements, 2005. 